\title{
Modification and Performance Evaluation of Hydroponic Structure with Nutrient Film Technique for Spinach
}

\author{
Ashwini D. Rathod ${ }^{*}$, Rajesh P. Murukar ${ }^{2}$ and Suchita V. Gupta ${ }^{3}$ \\ ${ }^{1}$ Department of Farm Structures, PGI, Dr. PDKV, Akola, India \\ ${ }^{2}$ Department of Farm Structure Dr. PDKV, Akola, India \\ ${ }^{3}$ Department of Farm Structures, College of Agril. Engg and Tech, Dr. PDKV, Akola, India \\ *Corresponding author
}

\section{A B S T R A C T}

\begin{tabular}{|l|}
\hline Ke y w o r d s \\
$\begin{array}{l}\text { Hydroponic Structure, } \\
\text { spinach, biometric } \\
\text { characteristics, uv- } \\
\text { polyethylene }\end{array}$ \\
\hline Article Info \\
\hline $\begin{array}{l}\text { Accepted: } \\
\text { 22 December } 2019 \\
\text { Available Online: } \\
\text { 20 January } 2020\end{array}$ \\
\hline
\end{tabular}

A field experiment was conducted to study the growth and quality of spinach under controlled atmosphere of hydroponic structure at Instructional Farm Department of Farm Structure, Dr. PDKV, Akola during February, 2019 - April, 2019. The experiment was laid out in randomized block design. The structure was $1400 \mathrm{~mm}$ long and $970 \mathrm{~mm}$ wide and at a height of $1800 \mathrm{~mm}$, OPI STAT statistical software was used for analyzes biometric characteristics and quality parameters respectively. The study indicated that the temperature, relative humidity, light intensity and $\mathrm{CO}_{2}$ inside the green hydroponic structure were favorable for the growth of spinach in the summer season. Green hydroponic structure showed better results followed by white and uv-polyethylene hydroponic structure. However, temperature inside the white and uv-polyethylene hydroponic structure was $1-3^{0} \mathrm{C}$ greater and also light intensity found maximum. Biometric characteristics of spinach like plant height, number of leaves and stem diameter was found maximum in green, white and uv-polyethylene hydroponic structure than open field. The yield was found maximum inside the green hydroponic structure. Yield on the open field was found 2 times less as compare to the green, white and uv-polyethylene hydroponic structure.

\section{Introduction}

Agriculture has been crucial for sustaining life and regularly improving technology to increase food production.

Technological advances in food production have been ample all over the world. Different methods of farming have strayed from the traditional system of soil based farming to the hydroponic techniques.
Soil less culture mainly refers to the techniques of Hydroponics and Aeroponic. The term Hydroponics was derived from the Greek words 'hydro' meaning water and 'ponos' meaning labour. It is a method of growing plants in soil less condition with their roots immersed in nutrient solution without soil. Soilless culture system using artificial substrates would result in efficient and effective use of water and fertilizers and minimize the use of chemicals for pest and disease control. Plants grown in soil less 
culture have consistently superior quality, high yield, rapid harvest, and high nutrient content.

Polyhouse farming as well as other modes of controlled environment cultivation has been evolved to create favorable micro-climates, conducive for crop production, making cultivation possible throughout the year or part of the year as required. Adopting soilless culture in protected cultivation with technical practices like integrated plant protection, fertigation, drip irrigation and climate control ensures better yield and water use efficiency. Therefore, studies over the last few decades have mainly focused on the development and rehabilitation of new or readily available systems especially aiming to provide more water and nutrient saving, increased yield and decreased waste of nutrients.

\section{Materials and Methods}

A field experiment on "Modification and Performance Evaluation of Hydroponic Structure with Nutrient Film Technique for Spinach" was conducted during 2018-19. This chapter gives the details of parameters considered for the experimental design and recording of data for the experimental study, procedure and instrumentation considered for conducting experiments and the methodology adopted for data analysis.

The experiments were conducted at Instructional Farm, Department of Farm Structures, Dr. Panjabrao Deshmukh Krishi Vidyapeeth, Akola, during the month of Feb April of 2018-19. The topography of the field was fairly uniform and leveled.

\section{Hydroponic Structure}

The easy to build modular hydroponic structure was used for conducting the experiment. Three hydroponic structures having different covering material were fabricated for the cultivation of spinach by nutrient film technique. The different covering material used were green, white and uv polyethylene. The structure was light weight and movable so that it can be move from one place to another place as per the convenience of crop environment. The structure was made up of un-plasticized polyvinyl chloride (UPVC) pipes of size $32 \mathrm{~mm}$ attached together to form an even pan type structure.

\section{Treatment details}

The field experiment was laid out in RBD with 8 replications and 4 treatments.

\section{Experimental details}

The details of experiments are given in Table.

\section{Nutrient Film Technique (NFT) system process}

Nutrient solution was pumped up from the tank to $2 \mathrm{~cm}$ diameter PVC pipe delivered to the top of the PVC pipe, the solution discharge in $75 \mathrm{~mm}$ PVC pipe was at the rate of $21 / \mathrm{min}$.

One side PVC pipe water slowly runs down the other end of PVC pipes.

The pipe was positioned at an angle to water flow at approximately $20-30 \mathrm{~mm}$ of depth inside PVC pipe.

The plants start to consume the nutrient rich water from bottom of PVC pipe, they begin to develop root systems inside the PVC pipes.

Water at the bottom of each pipe that the roots receive large amounts of oxygen at the root zone with water and nutrient.

This system supplied constant exchange of the water, nutrient and air to the plant.

The PVC pipes connected to the end cap 
excess water from the structures was returned into the tank and recirculated. The Structure was designed so that all the net cups got equal amount of water, nutrient and air

\section{Results and Discussion}

\section{Environmental parameters}

\section{Temperature}

During the experiment, the temperature was recorded at $8,11,14$ and 17 hours from $15^{\text {th }}$ February, 2019 to $30^{\text {th }}$ March, 2019 after the sowing of seeds. Table 3.1 and Table 3.2 showed average temperature in Fabruary and March green and white colour, and uvpolyethylene hydroponic structures and also average temperature on open field. Due to the controlled atmosphere system, temperature inside the green and white and uvpolyethylene hydroponic structure has great influence on crop growth. Temperature inside the green and white colour hydroponic structure was found $5-6^{0} \mathrm{C}$ less than the outside temperature. This difference was found due to the installation of floggers and exhaust fans, which helps in controlling the temperature. But as compared green and white structure, temperature inside the uvpolyethylene structure was greater by $3-2^{0} \mathrm{C}$ than green colour hydroponic structure. The results i obtained during the research work are represented graphically as shown in Fig 3.1 and Fig 3.2. Similar results have been reported for temperature (Meena et al., 2012) and (Meena et al., 2014).

\section{Relative humidity}

During the experiment, the relative humidity was recorded at $8,11,14$ and 17 hours. Table 3.3 and Table 3.4 shows average relative humidity in green and white colour and uvpolyethylene hydroponic structure and in the open field condition. The relative humidity inside the green and white colour and uvpolyethylene hydroponic structures was found to have great influenced on crop growth. In open field relative humidity was found minimum as compare to the green and white colour hydroponic structures during the growth stages of crop. The relative humidity inside the green and white colour and polyethylene hydroponic structure was observed in between $50-60 \%$ as on the open field relative humidity was found between 30 $40 \%$. The relative humidity inside green and white colour and uv-polyethylene hydroponic structure was found $19-20 \%$ more as compared to open field. But comparing green and white colour hydroponic structures, relative humidity inside the green colour hydroponic structure was found 3-4\% more than white and uv-polyethylene hydroponic structure. This difference was observed due to the controlled atmosphere management inside the hydroponic structure. Results obtained during the research work are shown graphically as shown in Fig 3.3 and Fig 3.4. Similar results have been reported for relative humidity (Meena et al., 2012) and (Meena et al., 2014)

\section{Light intensity}

During the experiment, the light intensity was recorded at $8,11,14$ and 17 from hours $15^{\text {th }}$ February, 2019 to $30^{\text {th }}$ March, 2019. Table 3.5 and Table 3.6 shows average light intensity in February and March green and white colour and uv-polyethylene hydroponic structure and on the open field condition. The light intensity inside the green and white colour and polyethylene hydroponic structures was found to have great influence on crop growth. In open field hydroponic structure light intensity was found maximum as compare to the green and white colour and uv-polyethylene hydroponic structures during the growing stages of crop. The light intensity inside the green and white colour hydroponic structure 
was observed in between $50-60 \%$ less as compare to open field and polyethylene. But as compare green white and uv-polyethylene hydroponic structure light intensity inside the green colour hydroponic structure was found 2-3\% less than white colour and polyethylene hydroponic structure. Results obtained during the research work are graphically as shown in Fig 3.5 and Fig 3.6. Similar results have been reported for light intensity (Meena et al., 2012) and (Meena et al., 2014).

\section{Effect of carbon dioxide $\left(\mathrm{CO}_{2}\right)$ on the growth of Spinach}

The $\mathrm{CO}_{2}$ concentration in the uv-polyethylene hydroponic structure was recorded higher in between 334.23 - $599.17 \mathrm{ppm}$ as compared to the white and green hydroponic structure and open field at all crop growth stages. This might be due to green and white colour decreases the crop temperature and vapour pressure deficit which leads to increase stomatal conductance and $\mathrm{CO}_{2}$ assimilate.
Among the covering material uv-polyethylene sheet reported highest $\mathrm{CO}_{2}$ concentration at all the crop growth stages. The open field conditions showed lowest $\mathrm{CO}_{2}$ concentration because of less photosynthetic rate and high temperature. The highest production of spinach was found in green hydroponic structure and lowest production was found in open field. Results obtained during the research work are graphically presented as shown in Fig 3.7.

\section{Biometric Characteristic}

\section{Height of the plant}

The plant height of spinach was influenced significantly due to different hydroponic structures and at all crop growth stages. Table 3.8 shown mean plant height influenced by different hydroponic structure at four days interval and the graphical representation of data is shown in Fig 3.8.

\section{Treatment details}

\begin{tabular}{|c|l|}
\hline Treatments & \multicolumn{1}{|c|}{ Specification } \\
\hline $\mathrm{T}_{1}$ & Green hydroponic structure with nutrient film technique \\
\hline $\mathrm{T}_{2}$ & White hydroponic structure with nutrient film technique \\
\hline $\mathrm{T}_{3}$ & UV-polyethylene hydroponic structure with nutrient film technique \\
\hline $\mathrm{T}_{4}$ & Open field condition hydroponic structure with nutrient film technique \\
\hline
\end{tabular}

\section{Experimental details}

\begin{tabular}{|c|l|c|}
\hline Sr. No. & Particulars & $\begin{array}{c}\text { Specification } \\
\text { Spinach }\end{array}$ \\
\hline 1. & Name of the crop & Spinaciaoleracea \\
\hline 2. & Scientific name & Savoy spinach \\
\hline 3. & Variety & Summer season \\
\hline 4. & Planting time & 4 \\
\hline 5. & Design & 8 \\
\hline 6. & Number of treatment & 4 \\
\hline 7. & Number of replication & 8 \\
\hline 8. & Total no of racks & 56 \\
\hline 9. & No of PVC pipe (Inside) & 7 \\
\hline 10. & No of plants (Inside) & 45 days \\
\hline 11. & No of plants per pipe & \\
\hline 12. & Duration of crop & \\
\hline & &
\end{tabular}


Table.1 Average temperature in month of February in GHS, WHS, PHS and OF

\begin{tabular}{|c|c|c|c|c|}
\hline \multirow{2}{*}{ Time $(\mathrm{Hrs})$} & \multicolumn{4}{|c|}{ Temperature $\left({ }^{\circ} \mathrm{C}\right)$} \\
\cline { 2 - 5 } & GHS & WHS & PHS & OF \\
\hline $8: 00$ & 19.10 & 21.09 & 22.12 & 24.50 \\
\hline $11: 00$ & 24.23 & 26.28 & 27.19 & 29.74 \\
\hline $14: 00$ & 32.22 & 34.24 & 35.26 & 37.33 \\
\hline $17: 00$ & 26.25 & 28.36 & 29.40 & 31.55 \\
\hline
\end{tabular}

Table.2 Average Temperature in month of March in GHS, WHS, PHS and OF

\begin{tabular}{|c|c|c|c|c|}
\hline \multirow{2}{*}{ Time (Hrs) } & \multicolumn{4}{|c|}{ Temperature $\left({ }^{0} \mathrm{C}\right)$} \\
\cline { 2 - 5 } & GHS & WHS & PHS & OF \\
\hline $8: 00$ & 23.15 & 25.10 & 26.12 & 28.12 \\
\hline $11: 00$ & 29.14 & 32.17 & 33.10 & 34.56 \\
\hline $14: 00$ & 32.41 & 34.19 & 35.41 & 38.57 \\
\hline $17: 00$ & 26.10 & 28.49 & 29.10 & 31.42 \\
\hline
\end{tabular}

Table.3 Average relative humidity in month of February in GHS, WHS, PHS and OF

\begin{tabular}{|c|c|c|c|c|}
\hline \multirow{2}{*}{$\begin{array}{c}\text { Time } \\
(\text { Hrs })\end{array}$} & \multicolumn{4}{|c|}{ Relative Humidity (\%) } \\
\cline { 2 - 5 } & GHS & WHS & PHS & OF \\
\hline $8: 00$ & 59.62 & 57.87 & 55.21 & 39.16 \\
\hline $11: 00$ & 57.11 & 55.44 & 52.12 & 36.24 \\
\hline $14: 00$ & 53.22 & 51.21 & 48.54 & 32.20 \\
\hline $17: 00$ & 55.16 & 53.44 & 50.11 & 34.10 \\
\hline
\end{tabular}

Table.4 Average relative humidity in the month of March in GHS, WHS, PHS and OF

\begin{tabular}{|c|c|c|c|c|}
\hline \multirow{2}{*}{$\begin{array}{c}\text { Time } \\
\text { (Hrs) }\end{array}$} & \multicolumn{4}{|c|}{ Relative Humidity (\%) } \\
\cline { 2 - 5 } & GHS & WHS & PHS & OF \\
\hline $8: 00$ & 56.32 & 54.21 & 52.54 & 36.32 \\
\hline $11: 00$ & 53.12 & 52.12 & 50.21 & 33.12 \\
\hline $14: 00$ & 51.26 & 49.44 & 47.21 & 30.26 \\
\hline $17: 00$ & 52.17 & 50.12 & 48.22 & 31.20 \\
\hline
\end{tabular}


Table.5 Average light intensity in the month of February in GHS, WHS, PHS and OF

\begin{tabular}{|c|c|c|c|c|}
\hline \multirow{2}{*}{$\begin{array}{c}\text { Time } \\
(\text { Hrs })\end{array}$} & \multicolumn{4}{|c|}{ Light intensity $\left(\right.$ Lux $\left.\times 10^{3}\right)$} \\
\cline { 2 - 5 } & GHS & WHS & PHS & OF \\
\hline $8: 00$ & 205.13 & 225.27 & 240.19 & 408.33 \\
\hline $11: 00$ & 260.41 & 280.11 & 295.87 & 512.12 \\
\hline $14: 00$ & 317.01 & 337.21 & 352.19 & 630.25 \\
\hline $17: 00$ & 230.25 & 250.31 & 265.41 & 456.21 \\
\hline
\end{tabular}

Table.6 Average light intensity in the month of March in GHS, WHS, PHS and OF

\begin{tabular}{|c|c|c|c|c|}
\hline \multirow{2}{*}{ Time $(\mathrm{Hrs})$} & \multicolumn{4}{|c|}{ Light intensity $\left(\right.$ Lux $\left.\times 10^{3}\right)$} \\
\cline { 2 - 5 } & GHS & WHS & PHS & OF \\
\hline $8: 00$ & 260.27 & 280.12 & 295.25 & 512.54 \\
\hline $11: 00$ & 320.09 & 340.12 & 355.16 & 634.18 \\
\hline $14: 00$ & 360.21 & 380.71 & 395.75 & 712.42 \\
\hline $17: 00$ & 295.54 & 315.54 & 330.54 & 587.09 \\
\hline
\end{tabular}

Table.7 $\mathrm{CO}_{2}$ concentration in GHS, WHS and OF at five days interval

\begin{tabular}{|c|c|c|c|c|}
\hline $\begin{array}{c}\text { Days/ } \\
\text { interval }\end{array}$ & \multicolumn{4}{|c|}{$\mathrm{CO}_{2}$ concentration (ppm) } \\
\cline { 2 - 5 } & GHS & WHS & PHS & OF \\
\hline 5 & 300.12 & 330.2 & 334.23 & 280.11 \\
\hline 10 & 325.74 & 346.14 & 350.56 & 299.1 \\
\hline 15 & 410.29 & 400.1 & 456.63 & 300.14 \\
\hline 20 & 468.42 & 450.25 & 497.28 & 325.24 \\
\hline 25 & 489.58 & 460.63 & 525.69 & 350.12 \\
\hline 30 & 499.89 & 480.87 & 555.74 & 365.87 \\
\hline 35 & 510.69 & 490.86 & 599.36 & 371.74 \\
\hline 40 & 525.23 & 500.1 & 603.17 & 385.45 \\
\hline 45 & 515.26 & 505.57 & 599.25 & 395.56 \\
\hline
\end{tabular}


Int.J.Curr.Microbiol.App.Sci (2020) 9(1): 2544-2555

Table.8 Mean plant height as influenced by different hydroponic structure at four days interval

\begin{tabular}{|l|l|l|l|l|l|l|l|l|l|l|}
\hline $\begin{array}{c}\text { Treatment/days } \\
\text { interval }\end{array}$ & 4 & 8 & 12 & 16 & 20 & 24 & 28 & 32 & 36 & 40 \\
\hline GHS & 2.13 & 2.78 & 3.32 & 3.8 & 4.03 & 4.8 & 5.26 & 5.71 & 6.26 & 6.86 \\
\hline WHS & 1.93 & 2.56 & 2.92 & 3.47 & 3.87 & 3.97 & 4.17 & 4.26 & 5.03 & 5.97 \\
\hline PHS & 1.15 & 2.42 & 2.91 & 3.25 & 3.48 & 3.88 & 4.07 & 4.15 & 4.82 & 5.57 \\
\hline OF & 0.92 & 1.43 & 1.67 & 1.91 & 2.18 & 2.73 & 2.95 & 3.65 & 4.43 & 4.38 \\
\hline C.D & 0.18 & 0.18 & 0.14 & 0.16 & 0.33 & 0.15 & 0.10 & 0.23 & 0.32 & 0.33 \\
\hline S.E(m) & 0.06 & 0.06 & 0.04 & 0.05 & 0.11 & 0.05 & 0.03 & 0.08 & 0.10 & 0.11 \\
\hline C.V. & 10.30 & 7.52 & 5.17 & 5.00 & 9.45 & 3.84 & 2.33 & 5.10 & 5.99 & 5.59 \\
\hline
\end{tabular}

Table.9 Mean of no. of leaves as influenced by different hydroponic structure at four-day interval

\begin{tabular}{|l|l|l|l|l|l|l|l|l|l|l|}
\hline $\begin{array}{l}\text { Treatment /days } \\
\text { interval }\end{array}$ & 4 & 8 & 12 & 16 & 20 & 24 & 28 & 32 & 36 & 40 \\
\hline GHS & 3.75 & 5.12 & 5.50 & 7.25 & 8.00 & 8.75 & 10.00 & 11.12 & 13.62 & 15.25 \\
\hline WHS & 3.50 & 4.25 & 4.50 & 4.37 & 6.65 & 7.37 & 8.25 & 8.87 & 9.87 & 9.87 \\
\hline PHS & 3.00 & 3.75 & 3.75 & 3.75 & 6.45 & 7.00 & 7.25 & 8.00 & 9.12 & 8.87 \\
\hline OF & 2.12 & 2.75 & 2.62 & 3.50 & 3.62 & 4.12 & 4.62 & 4.87 & 4.87 & 5.00 \\
\hline C.D & 0.83 & 0.76 & 0.88 & 0.98 & 0.44 & 0.68 & 0.61 & 0.62 & 0.91 & 0.83 \\
\hline S.E(m) & 0.28 & 0.25 & 0.29 & 0.33 & 0.14 & 0.23 & 0.20 & 0.21 & 0.30 & 0.28 \\
\hline C.V. & 25.82 & 18.36 & 20.58 & 19.97 & 6.89 & 9.54 & 7.75 & 7.24 & 9.31 & 8.14 \\
& & & & & & & & & & \\
\hline
\end{tabular}

Table.10 Mean stem diameter as influenced by different hydroponics structure at four days interval

\begin{tabular}{|l|l|l|l|l|l|l|l|l|l|l|}
\hline $\begin{array}{l}\text { Treatment/d } \\
\text { ays interval }\end{array}$ & 4 & 8 & 12 & 16 & 20 & 24 & 28 & 32 & 36 & 40 \\
\hline GHS & 0.088 & 0.141 & 0.221 & 0.286 & 0.349 & 0.434 & 0.493 & 0.573 & 0.634 & 0.833 \\
\hline WHS & 0.051 & 0.103 & 0.174 & 0.253 & 0.323 & 0.409 & 0.439 & 0.528 & 0.6 & 0.59 \\
\hline PHS & 0.043 & 0.093 & 0.16 & 0.241 & 0.313 & 0.394 & 0.423 & 0.489 & 0.523 & 0.579 \\
\hline OF & 0.026 & 0.069 & 0.114 & 0.198 & 0.275 & 0.336 & 0.37 & 0.404 & 0.433 & 0.466 \\
\hline C.D & 0.016 & 0.017 & 0.021 & 0.032 & 0.031 & 0.044 & 0.044 & 0.036 & 0.047 & 0.021 \\
\hline S.E(m) & 0.005 & 0.006 & 0.007 & 0.011 & 0.01 & 0.015 & 0.015 & 0.012 & 0.016 & 0.007 \\
\hline C.V. & 28.95 & 16.02 & 12.062 & 12.59 & 9.321 & 10.68 & 9.831 & 6.734 & 8.257 & 3.307 \\
\hline & 4 & & & 3 & & 6 & & & & \\
\hline
\end{tabular}


Fig.1 Average temperature in month of February

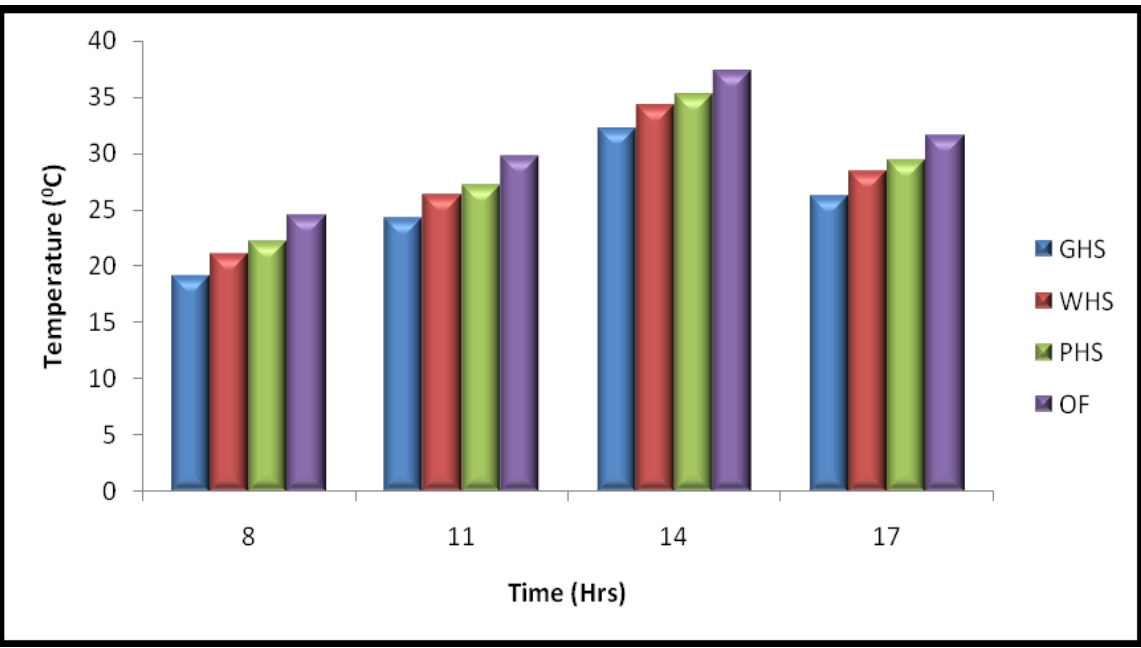

Fig.2 Average temperature in month of March

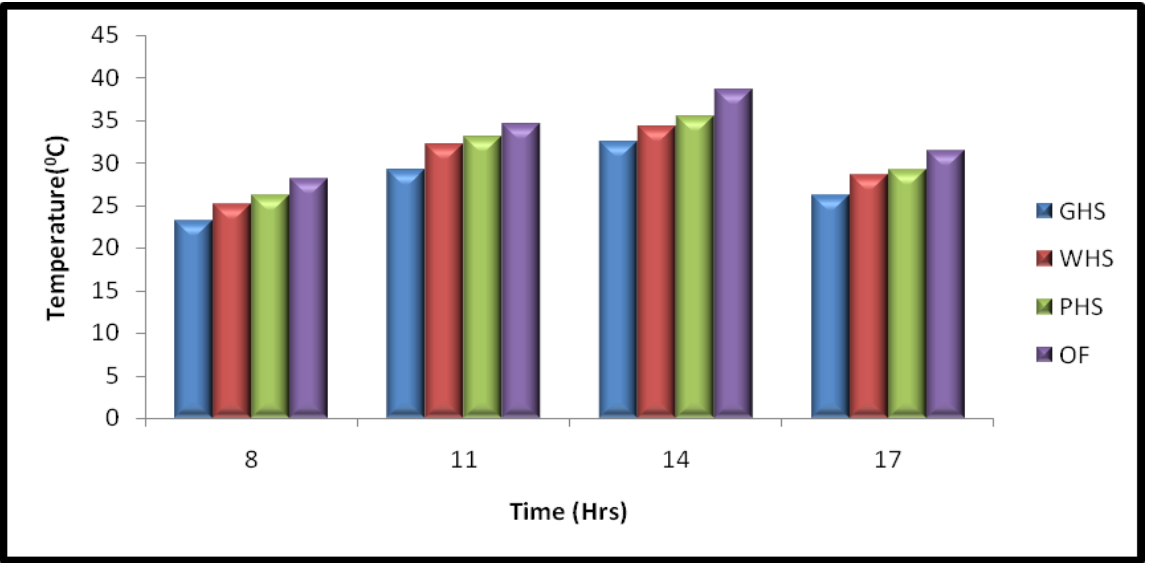

Fig.3 Average relative humidity in the month of February

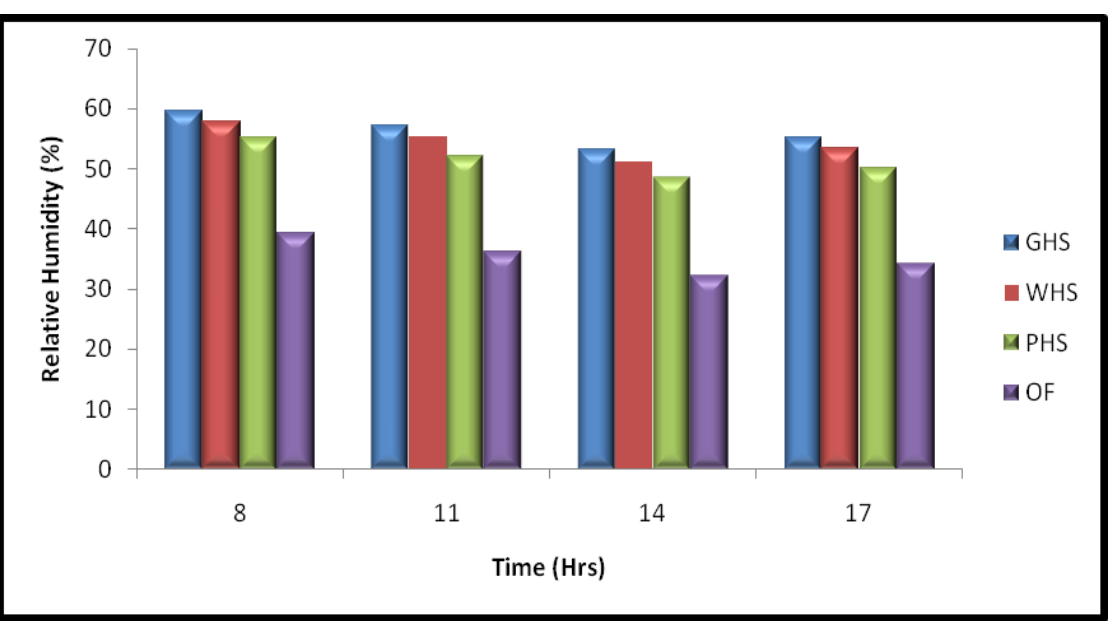


Fig.4 Average relative humidity in the month of March

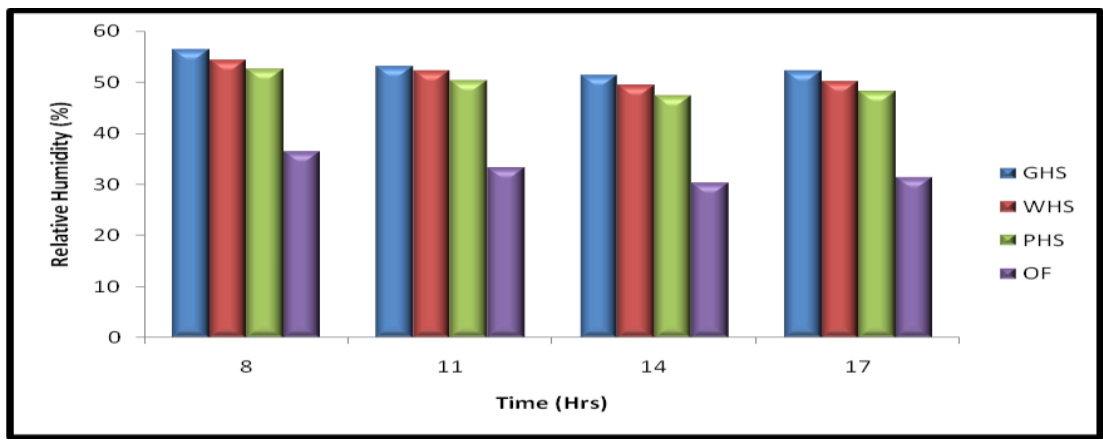

Fig.5 Average light intensity in the month of February

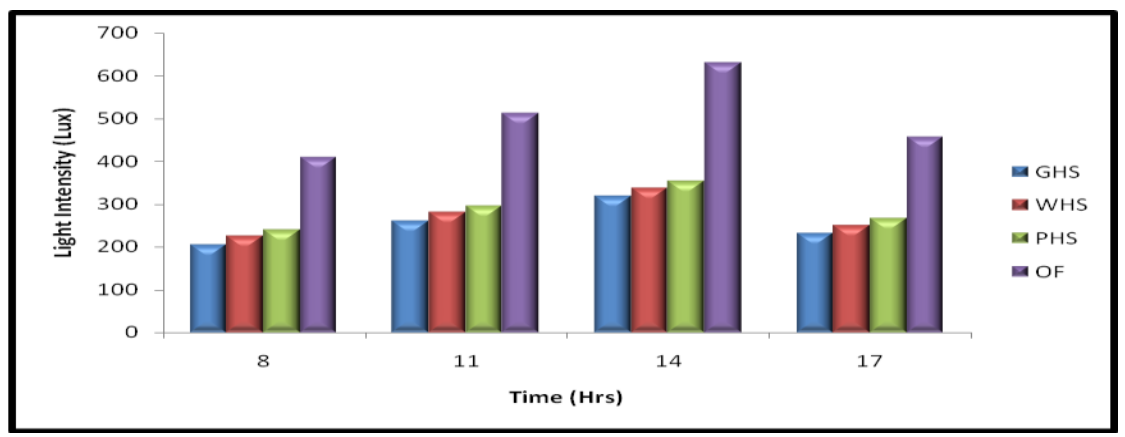

Fig.6 Average light intensity in the month of March

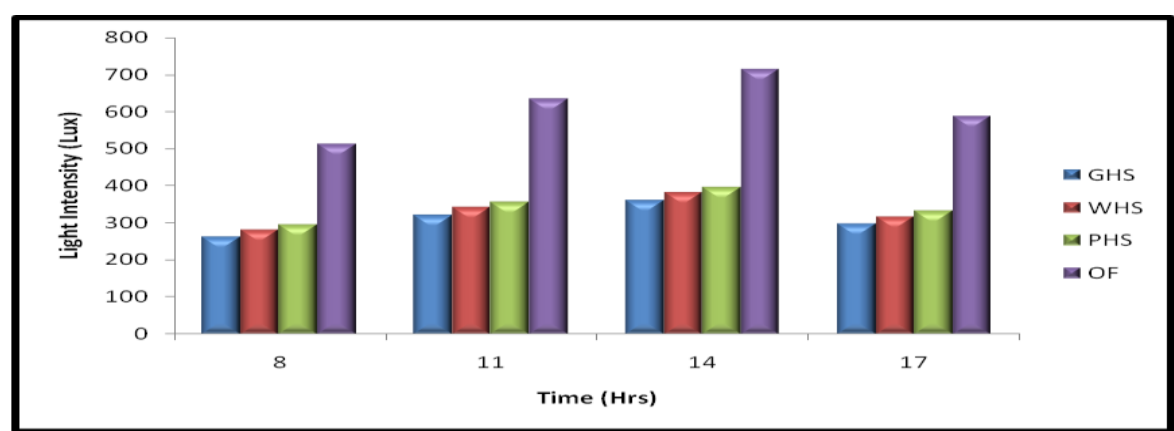

Fig.7 $\mathrm{CO}_{2}$ concentration at five days interval

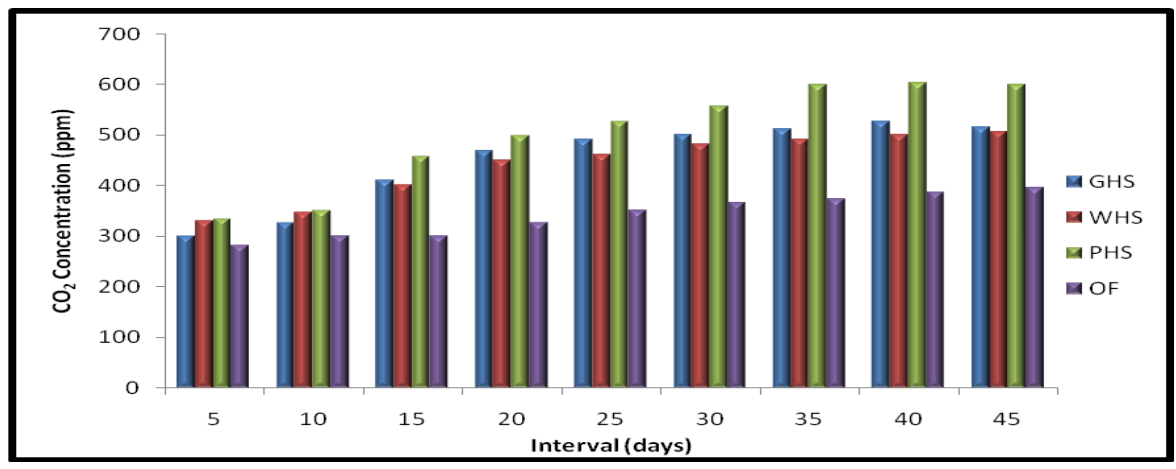


Fig.8 Average plant height of spinach at four days interval

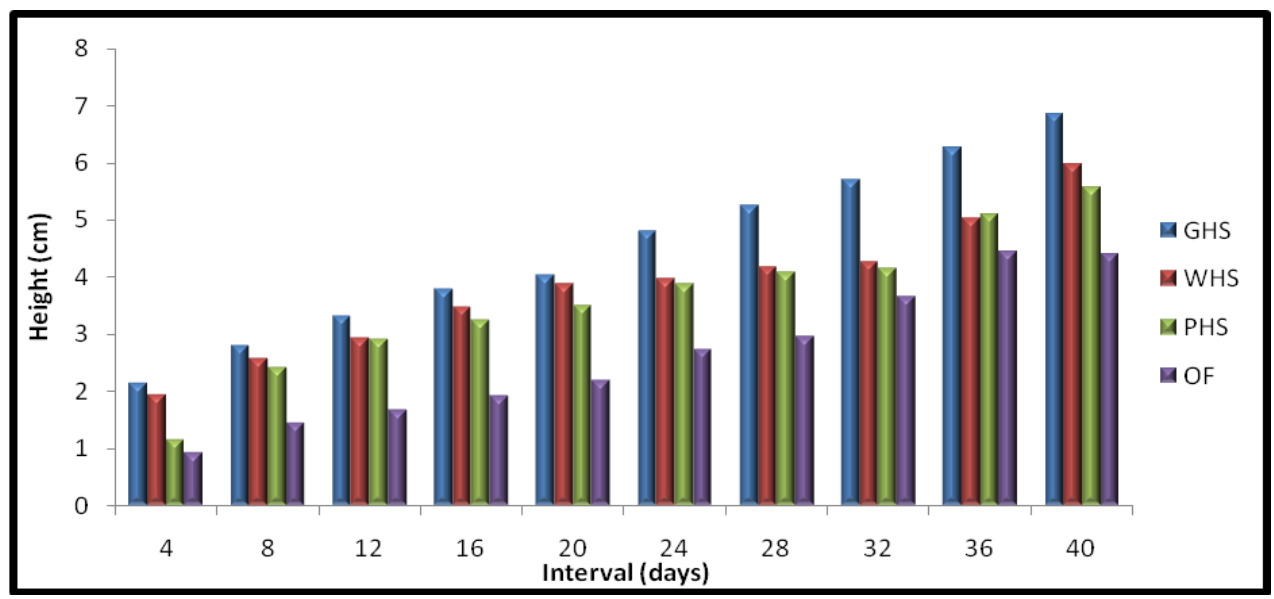

Fig.9 Average no. of leaves of spinach at four days interval

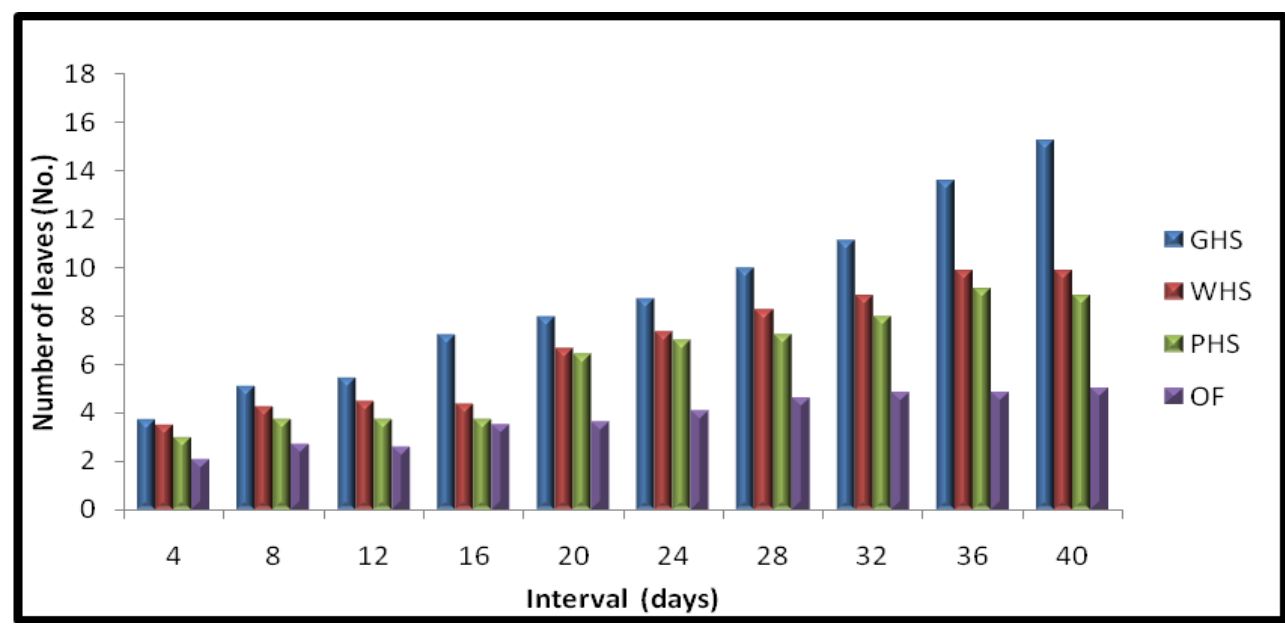

Fig.10 Average stem diameter of spinach at four days interval

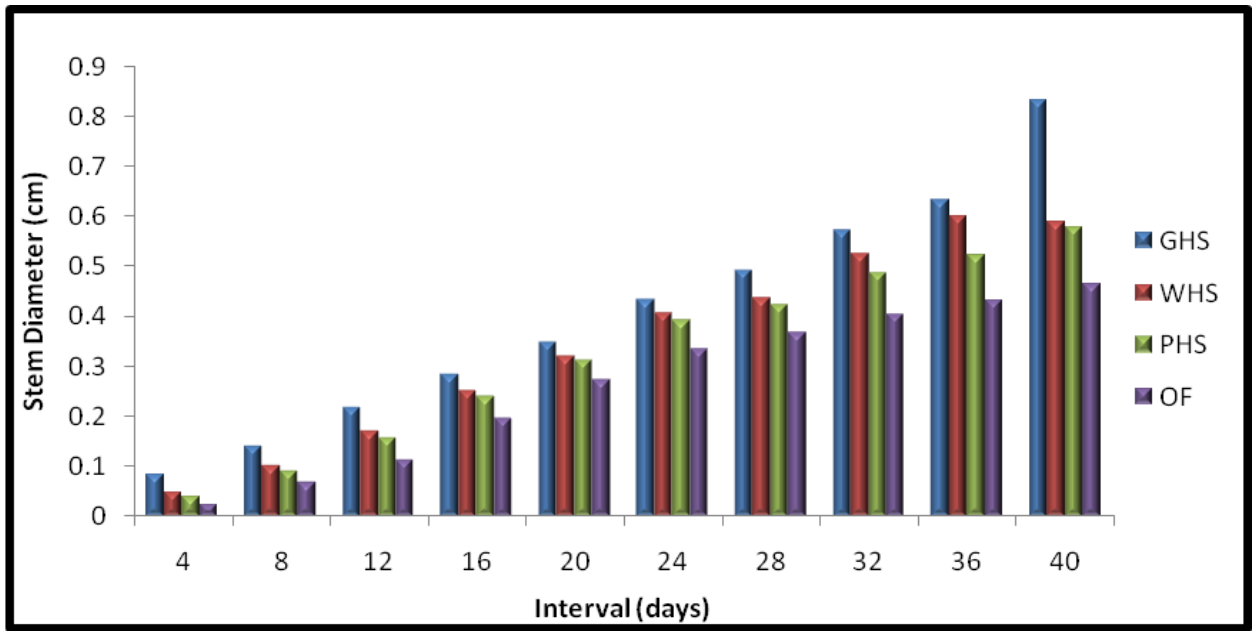


From Table 3.8, it was observed that during initial growth stage, at 8 and 12 days interval, height of plant was found at par. and the highest value of plant height were found in green hydroponic structure. It was found significantly lower in open field. At 16, 20, 24, 28, 32, 36, 40 day interval the height of plant was found at par. The highest value of plant height was found for the green hyroponic structure followed by white hydroponic structure followed by uvpolyethylene hydroponic structure.

Green hydroponic structure showed the better results compared to remaining three structures. It was found significantly lower in open field in all eight replicaions, height of spinach was found maximum $(6.86 \mathrm{~cm})$ inside green hydroponic structure at the time of harvest i.e at the end of 40 days.

\section{Number of leaves}

The number of leaves of spinach was found to be influenced significantly due to different hydroponic structures. Table 4.9 shows the mean number of leaves influenced by different hydroponic structures at four days interval and graphical representation of data is shown in Fig 4.9. The number of leaves measured at four days interval is given in Appendix VI.

From Table 3.9, it was observed that during initial growth stage, at $10^{\text {th }}$ day interval no. of leaves of plant was found at par. The highest value was found for green hydroponic structure. It was found significantly lower in open field. At 16, 20, 24, 28 32, 36, 40 day interval, no. of leaves of plant was found at par. The highest value was found for the green, followed by white hyroponic structure followed by uv- polyethylene hydroponic structure. it was found significantly lower in open field in all eight replications. The number of leaves of spinach was found maximum (15 Nos) inside the green hydroponic structure at the time of harvest.

\section{Stem Diameter}

The stem diameter of spinach was found to be influenced significantly due to different hydroponic structures at all crop growth stages. Table 3.10 shows mean stem diameter influenced by different hydroponic structure at four days interval and graphical represented as shown in Fig 3.10.

From Table 3.10, it was observed that during all growth stages at 8, 12, 16, 20, 24, 28, 32, 36, 40 days interval, stem diameter of plant was found at par. The highest value was observed for green hydroponic structure followed by white followed by uvpolyethylene hydroponic structure and open field. It was found significantly lower in open field. Stem diameter of spinach was found maximum $(8.83 \mathrm{~mm})$ inside the green hydroponic structure at the time of harvest.

\section{References}

Asker H S (2015) Hydroponic technology for lily flowers and bulbs production using rainwater and some common nutrient solutions. Afr J Biotechnol 14: 2307-13.

Avalhaes C C, Prado R M, Rozane D E, Romualdo L M and Correia M R (2009) Macronutrients omission and the growth and nutritional status of elephant grass (cv. Mott) growing in nutrient solution. SciAgrar 10: 215-22.

Barrett D.M., J.C. Beaulieu and S.T. Rob (2010). Color, flavor, texture, and nutritional quality of fresh-cut fruits and vegetables: desirable levels, instrumental and sensory measurement, and the effects of processing.

Behera B.P, R.R. Pattnaik, M. Das and J. Jena (2016). International journal of applied 
and pure science and agriculture (ijapsa). 2(8): 47-54.

Castillo F S, Perez E C, Pineda P J, Osuna J M, Perez J R and Encino T O (2014) Hydroponic tomato production with and without recirculation of nutrient solution. Agrociencia 48: 185-97.
Hochmuth G. and R. Hochmuth (2008) Design suggestions and greenhouse management for vegetable production in perlite and rockwool media in Florida. Horticultural Sciences Department. uf/ifas Extension, Bulletin 327.

\section{How to cite this article:}

Ashwini D. Rathod, Rajesh P. Murukar and Suchita V. Gupta. 2020. Modification and Performance Evaluation of Hydroponic Structure with Nutrient Film Technique for Spinach. Int.J.Curr.Microbiol.App.Sci. 9(01): 2544-2555. doi: https://doi.org/10.20546/ijcmas.2020.901.289 